\title{
Parental Job Loss and Early Child Development in the Great Recession
}

\author{
Gabriele Mari (iD) and Renske Keizer (iD \\ Erasmus University Rotterdam
}

\begin{abstract}
The study examines whether and why parental job loss may stifle early child development, relying on cohort data from the population of children born in Ireland in 2007-2008 $(N=6,303)$ and followed around the time of the Great Recession (2008-2013). A novel approach to mediation analysis is deployed, testing expectations from models of family investment and family stress.

Parental job loss exacerbates problem behavior at ages 3 and 5 (.05-.08 SDs), via the channels of parental income and maternal negative parenting. By depressing parental income, job loss also hampers children's verbal ability at age $3(.03 S D s)$. This is tied to reduced affordability of formal childcare, highlighting a policy lever that might tame the intergenerational toll of job loss.
\end{abstract}

Widespread job loss has been a prominent feature of the Great Recession and, within households, the consequences of job loss likely extend across generations. Previous research has either looked at the personal repercussions of job loss or at the longterm outcomes of children whose parents were displaced. These children typically under-perform their peers, at school (e.g., Rege, Telle, \& Votruba, 2011; Stevens \& Schaller, 2011) or in the labor market (e.g., Gregg, Macmillan, \& Nasim, 2012; Oreopoulos, Page, \& Stevens, 2008). Yet, most studies have linked parental job loss experienced during infancy to outcomes measured when offspring have reached adolescence or adulthood. What goes on during infancy itself has remained untapped, despite the potential for early interventions aimed at the equalization of life chances (e.g., Duncan \& Magnuson, 2013; Heckman, Stixrud, \& Urzua, 2006).

Hence, we focus on how parental job loss may affect children's early development, before and around school entry. Job displacement may affect parental income and parenting inputs, and both are

The present study was supported by a grant from the Netherlands Organization for Scientific Research (NWO MaGW VIDI grant no. 452-17-005 to Renske Keizer) and by a grant from the European Research Council (ERC StG grant no. 757210 to Renske Keizer). Data from Growing Up in Ireland were accessed via the Irish Social Science Data Archive-www.ucd.ie/issda. The authors wish to thank Geoffrey Wodtke, Katrien Helmerhorst, and Lisa van der Storm for their feedback and technical support, as well as participants in the 2019 Nederlandse Demografiedagen. Any errors or omissions are the authors' own. Replication materials are available at https://osf.io/e63rb/.

Correspondence concerning this article should be addressed to Gabriele Mari, Department of Public Administration and Sociology (DPAS), Erasmus University Rotterdam, Burg. Oudlaan 50, DR Rotterdam, The Netherlands. Electronic mail may be sent to mari@essb.eur.nl. central to family processes and child outcomes (Gershoff, Aber, Raver, \& Lennon, 2007; Khanam \& Nghiem, 2016; Layte, 2017; Washbrook, Gregg, \& Propper, 2014; Yeung, Linver, \& Brooks-Gunn, 2002). Income losses may impinge on parental investments that can foster children's cognitive development. Parenting in family environments burdened by economic and psychological stress may hamper behavioral adjustment in children. Cognitive and behavioral development at an early age in turn predicts success in school and the labor market (Conti \& Heckman, 2014; Heckman et al., 2006). The contribution of parental job loss to child outcomes via investment and parenting channels might thus shed light on why children of displaced parents are worse off later in life.

We combine three waves of Irish cohort data collected around the time of the Great Recession (Growing Up in Ireland [GUI], 2008-2013). Hit the hardest in OECD comparison, Ireland saw unemployment rates roughly treble for men and double for women during that period (Nolan \& Maître, 2017; Savage, Callan, Nolan, \& Colgan, 2019). The rise in unemployment was concentrated in the population under 35, and thus around the age of first parenthood and union formation in Ireland (Billari \& Liefbroer, 2010). Not surprisingly then, the chances for a dependent child to live below the

\footnotetext{
(C) 2021 The Authors

Child Development published by Wiley Periodicals LLC on behalf of Society for Research in Child Development.

This is an open access article under the terms of the Creative Commons Attribution-NonCommercial-NoDerivs License, which permits use and distribution in any medium, provided the original work is properly cited, the use is non-commercial and no modifications or adaptations are made. 0009-3920/2021/xxxx-xxxx
}

DOI: $10.1111 /$ cdev.13517 
poverty line and with a jobless parent increased by around half in the period (Nolan \& Maître, 2017).

Investigating widespread job loss and its consequences in a recent Irish cohort, our main contribution is thus twofold. First, we show that parental job loss is detrimental to early child development, expanding our current understanding of intergenerational dynamics tied to labor market turmoil (cf. Gregg et al., 2012). With respect to the few studies on early childhood (Peter, 2016), we provide a more comprehensive account, one that disentangles the influence of both paternal and maternal job loss, on both cognitive and behavioral outcomes, and at different time points before and around school entry. Second, we assess multiple paths via which parental job loss might have an impact on child outcomes. Complementing previous studies, we investigate the role of parental investments and family stress by implementing a novel approach to mediation analysis (Wodtke \& Zhou, 2020). This allows us to contribute to long-standing debates on family processes (Conger \& Donnellan, 2007), and also highlight levers at the disposal of policymakers to mitigate the toll of job loss across generations.

\section{Background: Job Loss From Parents to Children}

Many have examined whether children fare worse during adolescence and early adulthood if their parents were previously displaced or laid off. Most have found that paternal, but not maternal, job loss adversely affects children in the long term. Looking at plant closures in Norway, Rege et al. (2011) found that children of displaced fathers attain lower grade point averages in 10th grade. Similar results have been found in other contexts (Coelli, 2011; Gregg et al., 2012) and for other aspects of school performance such as grade retention (Stevens \& Schaller, 2011). On college enrolment, evidence also pointed to small negative effects of paternal job loss (Hilger, 2016), whereas findings for adult-life earnings have been more mixed (Bratberg, Nilsen, \& Vaage, 2008; Gregg et al., 2012; Hilger, 2016; Oreopoulos et al., 2008)hinting perhaps at a dilution of the influence of parental job loss over children's lifetime (but see, in contrast, Schmidpeter, 2020).

Even if small or diluted, these long-run effects might precipitate from responses to parental job loss during childhood. Recent research (Peter, 2016) supported the idea that job loss indeed creates obstacles to early development, as German children of a displaced mother show more behavioral problems at age 5-6 compared to their peers in observationally similar households where maternal job loss did not occur (see similar findings for school-age children in the United States, Hill, Morris, Castells, \& Walker, 2011). Paternal job loss may lead, according to a number of longitudinal studies, to a higher incidence of low birthweight and worse health across the board in young children (Lindo, 2011; Schaller \& Zerpa, 2019), which in turn are well-known correlates of cognitive and behavioral development (e.g., Currie, 2009).

These few studies prompt asking not just if, but also why parental job loss may hinder children's development. Mechanisms can be analytically distinguished based on two theoretical models, namely that of Family Investment (Becker \& Tomes, 1986; Leibowitz, 1974) and of Family Stress (Conger \& Donnellan, 2007). In accordance with the first, parental investments of time and money are crucial inputs in the production of child outcomes, particularly cognitive ones (e.g., Khanam \& Nghiem, 2016; Washbrook et al., 2014). These investments may be impaired or halted by job loss. Focusing on money, job loss depresses long-term earnings, particularly during recessions (e.g., Davis \& Von Wachter, 2011), and may thereby reduce a household's permanent income. Studies have consistently found evidence for substantial income losses, and yet, surprisingly, such losses seem to play little to no role in explaining the intergenerational effects of job loss (Bratberg et al., 2008; Hilger, 2016; Peter, 2016; Rege et al., 2011).

It could be though that much depends on the timing of job loss. Job losses around specific stages of children's educational trajectories might have a stronger impact. Schmidpeter (2020) found that parental unemployment, occurring around the time of early tracking in the Austrian school system (age 10), is most harmful for children's university completion chances and future earnings, the latter being measured as late as age 37 (see also Coelli, 2011). Focusing on the stages before and around school entry in our paper, the relevant educational investment decision likely involves formal childcare. This investment has been shown to generate developmental benefits for children, particularly in low-income households (e.g., Duncan \& Magnuson, 2013). Yet, similar to other Anglophone countries, net childcare costs can exceed $20 \%$ of disposable income for low-income households in Ireland (Browne \& Neumann, 2017, pp. 18-19). The Early Childcare Supplement, a yearly transfer introduced in 2006 to ease childcare costs, was first subject to cuts and then abolished by the end of 2009 (Nolan \& Maître, 2017). 
Irish households hit by job loss might have thus forgone investments in formal childcare and, via this channel, children exposed to parental job loss might lag behind in their development. This might go to the special detriment of the least well-off, although predictions are ambiguous. Parents with more resources, such as higher education, might be better poised to substitute formal childcare with educational inputs of their own (e.g., Fort, Ichino, \& Zanella, 2020). Despite their advantage "at the baseline," though, households with better-educated parents also had to bear the brunt of job loss in Ireland, with significant numbers sliding into joblessness and poverty during the recession (Nolan \& Maître, 2017). On the other hand, lower educated parents typically face more constraints combining their work schedules and child stimulation (e.g., Hsin \& Felfe, 2014). Job loss might make formal childcare unaffordable particularly in these households, but free up time for parent-child interactions. Job loss may thus simultaneously deplete economic investments and free up time investments in children, but how and to what avail-especially across households-merits a separate investigation.

Job loss may also affect families beyond parental investments and more in line with the pathways of Family Stress. Parenting, in particular, is the most proximate link between parents and children in the causal chain of Family Stress (e.g., Conger \& Donnellan, 2007). Evidence suggests that parental job loss, other than altering monetary (and time) inputs, might induce psychological distress among parents and ultimately fall on children by disrupting parenting. To begin with, it is well established that mental health deteriorates following job loss, and displaced spouses may adversely affect each other (Marcus, 2013; Mendolia, 2014). Poorer parental mental health has been associated with a kind of parenting that is lower in warmth, less consistent, and more hostile-leading then to heightened behavioral problems among children (for reviews, Pinquart, 2017a, 2017b). We expect that such "negative parenting" (e.g., Grant et al., 2003) might be more pronounced in response to maternal job loss as compared to paternal job loss, as studies have shown associations between maternal job loss and harsher or less sensitive parenting (e.g., McLoyd, Jayaratne, Ceballo, \& Borquez, 1994; Prickett, 2020), which could then explain poorer socioemotional development among children of displaced mothers (Hill et al., 2011; Peters, 2016). Yet, evidence has been largely confined to associations in small samples and specific groups (in particular, children of single mothers). Studies that aimed at identifying the causal effects of job loss in population-based samples, on the other hand, have lacked measures of parenting (e.g., Peter, 2016; Rege et al., 2011). By investigating the most proximate channel by which parents affect children in the Family Stress Model, we thus expand on and complement previous literature.

\section{Current Study}

Hence, this study examines the consequences of parental job loss before and around school entry for a large Irish cohort in the period 2008-2013. In doing so, we complement and further inform studies on the long reach of parental job loss in adolescence and adulthood. In light of how job loss may impinge on family investments and family processes, our study sets out with clear hypotheses more than being aimed to generate new ones. In particular, we expect negative consequences on children's development. Expanding on previous studies, we address these consequences in the cognitive and socio-emotional realm, for both are crucial for future life chances. We also consider paternal and maternal job loss, adding to a debate that has seldom compared the two at the same life stage of the offspring.

Figure 1 depicts not just the expected direct effect stemming from parental job loss but also its indirect components (as formalized in Equation 4 in Model Specifications section). We first concentrate on parental income, as income losses following job displacement may hinder subsequent childcare enrolment, especially in the relatively expensive and poorly subsidized context of Ireland during the Great Recession. Trade-offs between parental and external childcare may ensue, although with which consequences is unclear, particularly depending on parental education. Second, we consider parenting, and in particular a summary measure of "negative" parenting, to single out the stress channel via its most proximate link to child outcomes.

Together, these direct and indirect effects are hypothesized causal relations. We present them as such in Figure 1, accompanied by place-holders for those variables which might confound the relations of interest. These are clarified in the next section alongside our last and more methodological contribution, namely a "regression-with-residuals (RWR)" approach we believe can strengthen inferences regarding mechanisms.

\section{Method \\ GUI and the Study Sample}

Data were collected as part of GUI, a longitudinal study focused on children's developmental 


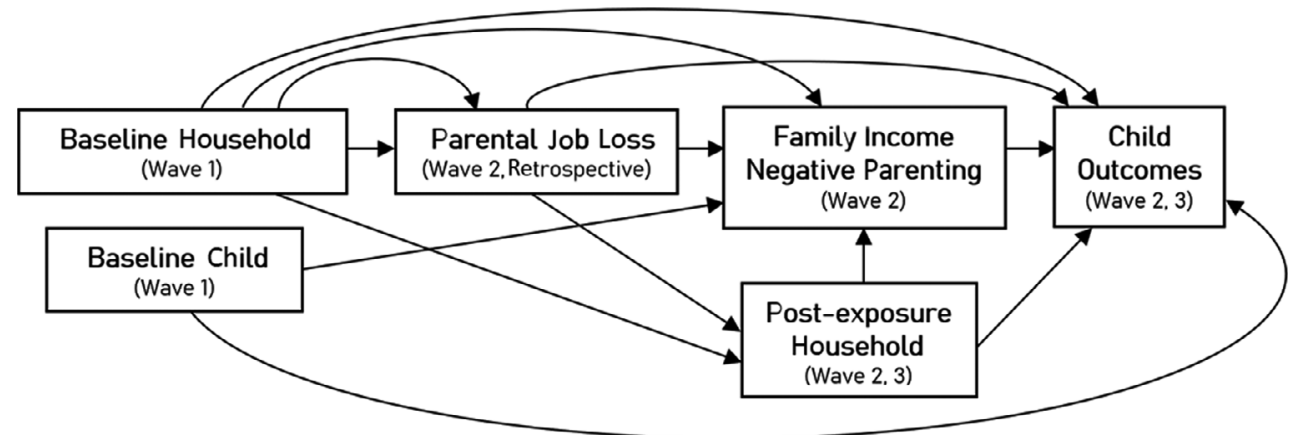

Figure 1. Main hypothesized causal relations between parental job loss and child outcomes, via the channels of family income and of negative parenting (see Equation 4 for a reference).

Note. Unmeasured confounding is assumed away and thus causal relations involving unobserved variables have been omitted. For simplicity, we also omit relations between "baseline household" and "baseline child" variables.

trajectories as well as on parental health, socioeconomic circumstances, and child-rearing practices (e.g., McCrory, Williams, Murray, Quail, \& Thornton, 2013). The child's mother is the primary respondent in most cases. Fathers, if present, are also interviewed in each wave. Children in the study were sampled from the Child Benefit register, covering all habitual residents in Ireland. Study children were born between December 1, 2007 and June 30, 2008. Conception and birth thus predate the Great Recession and especially precede the peak of unemployment recorded only later in Ireland, in 2011. Study children were 9 months old at the time of the first interview (Wave 1, 2008/2009) and we follow them at age 3 (Wave 2, 2011) and 5 (Wave 3, 2013). Effectively, we can thus count on one observation prior, one during, and one after the peak of the Great Recession (see also Reinhard, Layte, McCrory, Panico, \& Avendano, 2018).

A total of 11,134 households participated in Wave 1 of GUI, corresponding to a $70.2 \%$ valid contact response rate. Such sample numbers further amount to roughly one-third of all births in the December 2007-June 2008 period. Over Wave 2 and Wave 3, however, around $22 \%$ of the original sample was lost to follow-up. We restrict our analyses to households followed up to and including Wave 3 , and are thus left with 8,712 households. As noted by McCrory and others (2013, p. 14), loss to followup is "higher among more socially disadvantaged groups and one-parent families." To correct for this, we construct probability weights following procedures detailed in Appendix S1. Briefly, these entail the estimation of probability weights modeling the risk of loss follow-up via logistic regression and on the basis of a set of fully observed covariates mainly capturing family structure and socio- economic position. Probability weights, separately estimated for loss to follow-up between Wave 1 and Wave 2 and between Wave 2 and 3, are then combined via multiplication within each household (Robins et al., 2000; for a similar application, e.g., Kühhirt \& Klein, 2018).

We perform a number of additional sample exclusions. To account for these, we devise another probability weight (e.g., Seaman \& White, 2013) and combine it by multiplication with weights tackling loss to follow-up. First, an additional 1,649 observations had incomplete records on one or more measures deployed in this study and we perform listwise deletion. Out of the remaining 7,063 complete records, we further excluded 406 households in which either the mother or father of the study child never held a full-time job. We follow previous studies on the (intergenerational) effects of job loss (e.g., Jacobson, LaLonde, \& Sullivan, 1993; Schmidpeter, 2020) and limit our analysis to households with a minimum attachment to the labor market.

In line with previous studies using GUI (Reinhard et al., 2018), we also restrict our sample to families in which the mother of the study child remained the primary respondent across all waves. This is to ensure continuity in the assessments of the study child and avoid, vice versa, picking up differences over time that are due to inconsistencies across parental reports. As a result, 170 records were dropped, as they either listed the study child's father as the primary respondent in Wave 1 (17) or registered a change in the primary respondent in Wave 2 or 3 (153). Finally, we dropped 184 twoparent households in which both parents reported losing their job between Wave 1 and Wave 2. The small cell number prevents, regrettably, credible 
analysis of children's outcomes in this particular type of households. All our findings are substantially unchanged when including these households.

Our final sample comprises 6,303 households, around $72 \%$ of the GUI sample followed from Wave 1 to Wave 3 . Table 1 displays the baseline characteristics for the analytical sample, as measured in Wave 1. Our sample predominantly features two-parent households, of Irish descent, in which the mother has tertiary education and was employed full time prior to birth, not receiving any welfare payments, and belonging to more affluent income-quintile groups. Compared to vital statistics for Ireland, children's mothers are slightly older on average (by around 1 year) and children of nonIrish mothers are under-represented by a factor of 2 in our analytical sample (Central Statistics Office [CSO], 2009). With respect to the original cohort $(N=11,134)$ as well as the total sample after loss to follow-up but prior to listwise deletion $(N=8,712)$, our analytical sample has a skew toward more advantaged social strata, as signaled by lone-parent status, maternal education, ancestry, and parental income. The aforementioned weights counter this skew though: as displayed in Appendix S1 (Table 1S), minor differences between weighted and unweighted analyses, when present at all, do not alter our main conclusions. In the remainder, we will therefore stick to unweighted analyses.

Children in our sample are aged 3 and 5 when outcomes were measured (see below). This captures the stages before and around school entry, as Irish children can enroll in primary education from age 4 and must be enrolled by age 6 . Around $71 \%$ of children in our analytical sample are attending their first year of school (commonly called junior infants) at Wave 3 (age 5).

\section{Main Measures: Exposure, Outcomes, and Mediators}

In our study, we leverage the longitudinal nature of GUI by staggering our measures of exposure to parental job loss, child outcomes, and mediators thereof. Specifically, we consider the effects of parental job loss, occurred between Wave 1 and Wave 2, on children's cognitive and behavioral outcomes measured in Wave 2 and Wave 3, that is, when the child is 3 and 5, respectively. Mediators are measured at Wave 2: for a causal reading of our estimates, one has to assume not just that the mediator value is responsive to prior job loss but also that such value is not inversely affected by child outcomes. The latter assumption is less tenable when mediators and outcomes are measured contemporaneously (i.e., both at
Table 1

Baseline Sample Features of the Analytical Sample (Growing Up in Ireland, Wave 1)

\begin{tabular}{ll}
\hline & $\begin{array}{c}M(S D) / \\
\text { paseline sample features (Wave 1) }\end{array}$ \\
\hline Maternal age & $32.5(4.7)$ \\
Lone-parent household (ref. two-parent household) & .09 \\
Mother has tertiary education (ref. & .62 \\
$\quad$ upper-secondary or less) & \\
Mother employed part time prior to & .22 \\
$\quad$ birth (ref. employed full time) & .17 \\
Mother out of paid work prior to birth & \\
$\quad$ ref. employed full time) & .88 \\
Mother is of Irish descent (ref. not) & .17 \\
Household receives any welfare & \\
$\quad$ payment (ref. does not) & .17 \\
Parental income: Second quintile & \\
$\quad \quad$ (groups based on quintiles ${ }^{\mathrm{a}}$, ref. first) & .21 \\
Parental income: Third quintile & .25 \\
Parental income: Fourth quintile & .23 \\
Parental income: Fifth quintile & 6,303 \\
$N \quad$ &
\end{tabular}

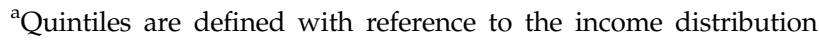
for the original cohort sample at W1.

Wave 2), and we will take this limitation into account when discussing our findings.

Building on previous research using GUI (Layte \& McCrory, 2018; Reinhard et al., 2018), we exploit survey items asking the primary respondent to indicate whether any of a series of changes "due to the recession" occurred since the previous interview (McCrory et al., 2013). Among them, respondents were asked whether they or their partner "were made redundant or lost their job due to the recession." We use information collected in Wave 2 to distinguish children exposed to one of three conditions between Wave 1 and Wave 2, namely (a) paternal job loss (16.3\%), (b) maternal job loss $(8.1 \%)$, and (c) no job loss $(75.6 \%$, the reference group). Similar to other studies based on survey data (Peter, 2016; Stevens \& Schaller, 2011), our measure of parental job loss is thus a self-report and much relies on respondents' ability to correctly assess the reasons underlying job loss.

Despite this limitation as compared to, say, register data on plant closures (e.g., Rege et al., 2011), our data are rich on early developmental outcomes rarely available outside of surveys. Furthermore, the availability of two measurements, at ages 3 and 5, may allow us to uncover effects that mature over time or, vice versa, wane already around pre-school age. We first track children's cognitive development 
in terms of verbal ability, as assessed via the Naming Vocabulary subtest of the British Ability Scales, 2nd ed. (BAS-II; Elliot, Smith, \& McCulloch, 1997; Hill, 2005). In this subtest, the child is tasked with identifying and naming different objects in a colored booklet. The test was administered in person by a general-purpose interviewer, aided by a CAPI program that tailored the question order to the response pattern of the child (McCrory et al., 2013). Test scores measure children's expressive (English) vocabulary and knowledge of nouns, two are components of General Conceptual Ability (Hill, 2005). At its inception, the test proved to have good interitem reliability $(\alpha=.78-.86$, depending on the age of the child) and to correlate highly with other measures of cognitive ability, such as with the verbal IQ component of WPPSI-R, the Wechsler Preschool and Primary Scale of Intelligence-Revised $(r=.68$, Elliot et al., 1997). Similar to previous research also relying on BAS (e.g., Kühhirt \& Klein, 2018), we take the ability scale which corrects for differences in item difficulty. We standardize ability scores to express our findings in terms of $z$-scores.

In terms of behavioral development, we employ measures from the Strengths and Difficulties Questionnaire (SDQ, e.g., Goodman \& Goodman, 2009), an extensively validated screening tool for psychopathology in children and adolescents. SDQ measures have also been shown to generate returns in school and the labor market (Conti \& Heckman, 2014; Currie, 2009) and to be responsive to parental resources and parenting practices (e.g., Khanam \& Nghiem, 2016; Layte \& McCrory, 2018; Washbrook et al., 2014). Five subscales can be derived from the questionnaire, administered here to the mother of the study child. The subscales tap emotional symptoms, hyperactivity/inattention, conduct problems, peer problems, and prosocial behavior. For our analyses, we rely on composite measures following previous studies (e.g., Goodman, Lamping, \& Ploubidis, 2010; Kiernan \& Huerta, 2008). We combined measures for emotional symptoms and peer problems into a single score for internalizing problems. Conversely, we summed the scores for conduct problems and hyperactivity/inattention to obtain a measure of externalizing problems. Parental reports for both measures have proven reliable in previous research $\left(\alpha_{\text {Internalizing }}=.73, \alpha_{\text {Externalizing }}=.78\right.$; Goodman et al., 2010, p. 1186) and predictive, for example, of later attention deficit hyperactivity disorder diagnoses (ibidem).

We further rely on one main measure for each channel via which parental job loss might affect child outcomes. We first consider parental economic inputs in the form of gross annual household income, reported by the primary respondent at Wave 2. Following common practices, we then take the logarithm of this measure. As noted elsewhere (Khanam \& Nghiem, 2016), taking the log reflects the assumption that child outcomes might linearly co-evolve with parental income but only up to a point, after which additional income might produce diminishing returns for children.

Finally, we consider the $z$-scores of a composite measure of maternal negative parenting, tapping this input also at Wave 2. Parenting measures in GUI are self-reported and derived from 17 items adopted from the Longitudinal Study of Australian Children (LSAC; Zubrick, Lucas, Westrupp, \& Nicholson, 2013). These items are summed to obtain scores for three parenting dimensions, namely hostility, warmth, and consistency. Parental warmth is characterized by displays of affection and an awareness of the child's needs (captured by items such as "How often do you express affection by hugging, kissing and holding this child?"), parental hostility refers to negativity and frustration directed toward the child and use of physical discipline (e.g., "I have lost my temper with this child"), whereas parenting consistency involves setting and consistently applying age-appropriate rules and expectations (e.g., "When you give this child an instruction or make a request to do something, how often do you make sure that he/she does it?"). Good internal reliability was found for each dimension in LSAC (see $\mathrm{H}$ coefficients, Zubrick et al., 2013, pp. 20-23) and internal consistency proved satisfactory in the Dress Rehearsal phase of GUI ( $\alpha_{\text {Warmth }}=.73, \alpha_{\text {Consistency }}=$ $.68 ; \alpha_{\text {Hostility }}=.62$; McCrory et al., 2013, p. 49).

We build an overall measure of "negative" parenting to reflect the common finding that children's problem behavior is similarly spurred by parenting that is low in warmth and consistency, and high in hostility (Grant et al., 2003; Pinquart, 2017a, 2017b). We use the attribute "negative," therefore, in light of the expected detrimental effects on child outcomes, and not with reference to the explicit presence of negative behavior within each dimension (e.g., low warmth/consistency is not necessarily negative behavior, in the same way high hostility can be). We reverse code warmth and consistency and combine them with hostility in a single variable, using the score predicted by principal component analysis (e.g., Hinshaw et al., 2000; Psychogiou, Daley, Thompson, \& Sonuga-Barke, 2007). Negative effects may thus derive from high hostility, low warmth/consistency, or a combination of all of these. A caveat when building such a 
summary measure is thus the impossibility of disentangling the contribution of each dimension or of each possible combination of these three dimensions.

We focus on maternal reports as the father may not always be present, for example in lone-parent households. In two-parent households, we thus proceed on the assumption that paternal job loss may have cross-over effects on the partner and be reflected in her parenting (Marcus, 2013; Mendolia, 2014). To be sure, we acknowledge that commonmethod bias may ensue, as measures of both parenting and problem behavior are based on maternal reports and this may inflate their association.

\section{Model Specifications}

In our analyses, we aim, first, at estimating the total effects of parental job loss on child outcomes via the following regression specifications:

$$
\begin{gathered}
D_{i j w}=a_{i j w}+\beta_{1} \mathrm{PJL}_{i}+\beta_{2} \mathrm{MJL}_{i}+\delta \mathbf{C}_{i}+\varepsilon_{i j w}, \\
D_{i j w}=a_{i j w}+\beta_{1} \mathrm{PJL}_{i}+\beta_{2} \mathrm{MJL}_{i}+\delta \mathbf{C}_{i}+\gamma \mathbf{B}_{i}+\varepsilon_{i j w},
\end{gathered}
$$

where $D_{i j w}$ stands for one of $j$ developmental outcomes, as measured for a given child $i$ in waves $w=2,3$. Both specifications include our main coefficients of interest, $\beta_{1}$ and $\beta_{2}$, respectively associated with paternal job loss $\left(\mathrm{PJL}_{i}\right)$ and maternal job loss $\left(\mathrm{MJL}_{i}\right)$. Households with no job loss registered between Wave 1 and Wave 2 are part of the comparison group, and thus the omitted reference category for this polytomous exposure. Equations 1 and 2 then differ in terms of the additional covariates. In Equation 1, we only include a vector of child characteristics $\mathbf{C}_{i}$ recorded at Wave 1 . These are sex of the child, dummies for birth order, a counter for the number of siblings, and a dummy for low birthweight $(<2,500 \mathrm{~g})$. We also add scores for three domains-communication, problem solving, and personal/social —of the Ages and Stages Questionnaire (e.g., Squires, Bricker, \& Potter, 1997). We take assessments when the child was 8 months to adjust for children's prior cognitive endowments (e.g., Charkaluk et al., 2017). To tap into precursors of problem behavior at the baseline, we consider four dimensions of child temperament ("fussy/difficult," "unadaptable," "unpredictable," and "dull"), as reported by the mother at the 9-month mark and based on the Infant Characteristics Questionnaire (Bates, Freeland, \& Lounsbury, 1979). We expect all these child features $C_{i}$ to only affect child outcomes, and not to influence the odds of parental job loss.
Their inclusion may enhance the precision of estimates of $\beta_{1}$ and $\beta_{2}$ in Equation 1. This first specification thus provides a benchmark of the total association between parental job loss and child outcomes.

Next, with Equation 2, we probe these associations to the inclusion of $\mathbf{B}_{i}$. This vector comprises a set of maternal and household characteristics that may affect child outcomes and the odds of experiencing parental job loss (see also Watson, Whelan, Maître, \& Williams, 2015). Despite bringing about widespread job loss, the Great Recession did not increase the odds of job loss at random. Job and income losses were concentrated, for example, among workers below 35 and among the middle and lower end of the income distribution (Nolan \& Maître, 2017; Savage et al., 2019). The vector $\mathbf{B}_{i}$ thus includes the following set of covariates, all measured at Wave 1 and thus prior to job loss: a quadratic for maternal age at birth, dummies for maternal education, maternal work status prior to birth, whether the mother is married to or cohabiting with her partner, whether the mother is of Irish descent, whether anyone in the household receives welfare payments, equivalized household income (dummies based on quintiles). $\mathbf{B}_{i}$ also comprises self-reported scores for maternal depression (CESD; Radloff, 1977) and maternal attachment (Condon \& Corkindale, 1998). Rather than confounding between job loss and child outcomes, these two variables aim at capturing confounding of the family-stress mediation pathway that we will illustrate in the next section. We include them from the start, nonetheless, for consistency.

These variables are aimed at curbing confounding bias from our estimates, as depicted in Figure 1. To grant a causal interpretation to our estimates, we thus rely on a selection on observables assumption in line with previous observational literature (e.g., Peter, 2016). In short, our estimates approximate the (total) causal effect of parental job loss on child outcomes if and to the extent that $\mathbf{B}_{i}$ incorporates a sufficient set of variables to block all spurious paths between exposure and outcome.

\section{Mediation Analyses}

On top of the total effect of job loss, our concern lies with the mediating paths linking parental job loss to early child development, either via income or parenting inputs. We therefore set up a formal mediation analysis (e.g., VanderWeele, 2015) to identify direct and indirect effects of job loss under a set of assumptions. Specifically, we identify causal 
direct and indirect effects only by blocking all spurious paths not just between exposure and outcome, as per Equation 2, but also between the exposure and the mediator of interest, as well as between the latter and the outcome. Several of the variables predating job loss and included in both $\mathbf{C}_{i}$ and $\mathbf{B}_{i}$, for example, can serve these purposes. For one, both child temperament and maternal depression (attachment) at the baseline might confound the relation between maternal negative parenting and child outcomes in later waves.

As per Figure 1, other sources of mediator-outcome confounding, however, could take their value "post exposure," being affected by the exposure itself. If we were to adjust for such post-exposure variables in our regressions, though, we would bias the effects of job loss by (a) "controlling away" some of the paths via which these effects operate in the first place, and by (b) possibly inducing collider stratification bias (e.g., VanderWeele, 2015, p. 342). To move past these hurdles, we follow a RWR approach (Wodtke \& Zhou, 2020). This novel approach allows, in short, to purge the problematic association between exposure and some candidate confounders via simple regression residualization, so that these variables can then be safely included when investigating mediation.

We specifically consider parental separation, the birth of a sibling, and whether the family moved as events that may have been influenced by parental job loss (e.g., Huttunen, Møen, \& Salvanes, 2018) and that might induce mediator-outcome confounding. For child outcomes at Wave 2, we consider these variables as measured at Wave 2, whereas for outcomes at Wave 3 we also incorporate the birth of an additional sibling and parental separation as measured at Wave 3. Differently from Wave 2, we have no information on family moves in Wave 3 and this post-treatment variable could not be added to our models.

In practice, RWR involves four steps. First, we center pre-exposure variables around their unconditional sample mean, thus obtaining mean-centered vectors $\hat{\mathbf{C}}_{i}^{\perp}$ and $\hat{\mathbf{B}}_{i}^{\perp}$ from the original $\mathbf{C}_{i}$ and $\mathbf{B}_{i}$. Variables in these sets take their value prior to parental job loss and thus we do not need to purge their association with it. Second, for each candidate post-exposure confounder we fit a model with all pre-exposure variables and the exposure as covariates, and then extract the residuals. Throughout we fit linear probability models for our post-exposure variables and enclose their residualized counterpart in the vector $\hat{\mathbf{L}}_{i}^{\perp}$.
Step three involves fitting two models, one for the mediator of interest and one for the outcome. These are as follows:

$$
\begin{gathered}
M_{i m}=\alpha_{i m}+\theta_{1} \hat{\mathbf{C}}_{i}^{\perp}+\theta_{2} \mathrm{PJL}_{i}+\theta_{3} \mathrm{MJL}_{i}+\varepsilon_{i m}, \\
D_{i j w}=\alpha_{i j w}+\delta_{1} \mathrm{PJL}_{i}+\delta_{2} \mathrm{MJL}_{i}+\gamma_{1} M_{i m}+\gamma_{2} \mathrm{PJL}_{i} M_{i m} \\
+\gamma_{3} \mathrm{MJL}_{i} M_{i m}+\omega \hat{\mathbf{C}}_{i}^{\perp}+\phi \hat{\mathbf{L}}_{i}^{\perp}+\varepsilon_{i j w},
\end{gathered}
$$

where $M_{i m}$ in Equation 3 is one of $m=\{\log$ of household income, negative parenting\} mediators of interest. Equation 4 is the full outcome model, including the mediator of interest and residualized post-exposure variables $\hat{\mathbf{L}}_{i}^{\perp}$. Net of their association with parental job loss thanks to residualization, post-exposure variables help de-confounding the association between a given mediator $M_{i m}$ and child outcome $D_{i j w}$ in Equation 4. Our model in Equation 4 also allows for interactions between exposures and a given mediator, here expressed by coefficients $\gamma_{2}$ and $\gamma_{3}$. This flexible specification has been advocated for as the default in the literature on causal mediation (e.g., VanderWeele, 2015, pp. 46-47). In our setting, assuming away such interaction may prove unrealistic if, for example, the effects of household income on child outcomes are stronger in households that have been exposed to, say, paternal job loss rather than no job loss at all or maternal job loss.

Having specified Equation 4, the fourth and last step involves deriving direct and indirect effects. RWR helps retrieve the so-called randomized natural direct effect, or R-NDE, and randomized natural indirect effect, or R-NIE (e.g., VanderWeele, 2015, pp. 135-136). Focusing on paternal job loss for illustrative purposes, the R-NDE and R-NIE are derived from Equations 3 and 4 as follows (Wodtke \& Zhou, 2020):

$$
\begin{gathered}
\overline{\mathrm{R}-\mathrm{NDE}}=\left[\hat{\delta}_{1}+\hat{\gamma}_{2} \cdot\left(\hat{\alpha}_{i m}+\hat{\theta}_{2}\right)\right] \cdot\left(a^{*}-a\right), \\
\overline{\mathrm{R}-\mathrm{NIE}}=\left[\hat{\theta}_{2} \cdot\left(\hat{\gamma}_{1}+\hat{\gamma}_{2} a^{*}\right)\right] \cdot\left(a^{*}-a\right),
\end{gathered}
$$

where $a^{*}$ and $a$ stand for two values of our exposure. Operationally, this entails switching from the value of the reference category of no job loss to, say, paternal job loss, that is $(1-0)=1$. The difference $\left(a^{*}-a\right)$ is meant to represent a counterfactual intervention, one in which all population analogues of our sample members experience paternal job loss $\left(a^{*}\right)$ rather than no job loss at all $(a)$. Similar considerations apply to maternal job loss. 
The R-NDE then captures the direct effect of paternal (maternal) job loss with the mediator set at a value randomly selected from its distribution under the reference level of the exposure (no job loss), given covariates. For intervention or policy purposes, this captures the effect of parental job loss via other channels than through the mediator of interest. Conversely, the R-NIE expresses what would be the expected difference in the outcome if all children were counterfactually exposed to paternal (maternal) job loss, and contrasting outcomes when the mediator is randomly selected among its distribution for those exposed to paternal (maternal) job loss rather than not exposed (no job loss). This latter estimate provides us with the effect of parental job loss on child outcomes via the channels of household income or maternal negative parenting, suggesting what would happen if we were to intervene only on how these mediators change in response to job loss. Finally, the R-ATE (randomized average total effect) equals the sum of RNDE and R-NIE. It is defined as an average total effect that contrasts the levels of the exposure (say, paternal job loss against no job loss), assuming an additional randomized intervention on the mediator.

Standard errors and confidence intervals are computed using the non-parametric bootstrap (with 200 replications). All analyses are carried out using Stata/MP 16.1, adapting code from the Stata package rwrmed (see Wodtke \& Zhou, 2020).

\section{Results}

\section{Parental Job Loss and Early Child Development}

We report our main findings in Table 2. All models contrast paternal and maternal job loss to the reference of no job loss at all. At age 3, paternal job loss seemingly leads to a small reduction in a child's vocabulary score, of around .08 of a $S D$ $(p=.022)$. This holds when adjusting only for child features in Model 1. For maternal job loss, vice versa, the estimate is positive, but we cannot detect an association $(p=.448)$. Turning to Model 2 , and thus accounting for baseline maternal and household characteristics, our estimate for maternal job loss is largely unchanged, yet that for paternal job loss reduces to .02 of a $S D$ (and $p=.491$ ). Most of the total effect of paternal job loss on vocabulary scores seems thus due to measured confounding, whereas the association between our cognitive measure and maternal job loss is, unexpectedly, positive.
Moving on to behavioral adjustment at age 3, we find that paternal job loss is associated with an increase of around one-tenth of a $S D$ in both internalizing and externalizing problems, focusing on Model 1. In both cases, estimates halve when maternal and household characteristics are adjusted for. In Model 2, indeed, we find an association of around .06 of a $S D$ for internalizing problems $(p=.081)$ and .05 of a $S D$ for externalizing problems $(p=.114)$. The associations between maternal job loss, on the other hand, and behavioral adjustment at age 3 are often smaller in size and more noisy, although in the expected direction (.04 for internalizing problems, $p=.370$; .003 for externalizing problems, $p=.941$ ).

In the lower panel of Table 2, we examine whether the effects of parental job loss during the economic downturn persisted or matured by the time children turned 5 . In response to paternal job loss, we find again a reduction in children's vocabulary of around .08 of a $S D$ in Model $1(p=.014)$, that more than halves to .03 of a $S D$ in Model 2 $(p=.379)$. For maternal job loss, estimates are this time negative and rather similar across models, hovering around a reduction of $.08 S D$ in Model 1 $(p=.060)$ and .07 of a $S D$ in Model $2(p=.120)$.

As for internalizing problems at age 5 , we find little evidence of associations with parental job loss. When it comes to the association between internalizing problems and paternal job loss in particular, there might thus be some dissipation as children grow older. On the contrary, for externalizing problems, we find stable or even reinforced associations. Paternal job loss is still associated with an increase of .10 SDs for externalizing problems in Model 1, an estimate that roughly halves in Model 2 $(p=.141)$. This mirrors the pattern found at age 3 . Maternal job loss is associated instead with a .9-.11 increase in the $z$-score for externalizing problems at age 5, a significant jump from the previous assessment at age 3 .

The two snapshots at ages 3 and 5 presented in Table 2 bring a host of developmental implications. There are synthesized in Figure 2, where we present average $z$-scores for each outcome and age of the child, across four conditions: the observed sample average for all children ("Raw"), as well as predicted scores (based on Model 2) under the three scenarios of no job loss, paternal job loss, and maternal job loss. All outcomes are normalized at age 3, that is, expressed in terms of SDs of the corresponding $z$-score at age 3 , to further compute a meaningful "developmental delta" between the two time points. Average scores at age 3, thereby, equal 0, 
Table 2

OLS Models for Parental Job Loss and Child Outcomes (z-Scores) at Ages 3 and 5. Model 1 Adjusts for Child Features, Model 2 Adds Baseline Maternal and Household Features (Unweighted, Growing Up in Ireland 2008-2013)

\begin{tabular}{|c|c|c|c|c|c|c|}
\hline & \multicolumn{2}{|c|}{ Vocabulary } & \multicolumn{2}{|c|}{ Internalizing problems } & \multicolumn{2}{|c|}{ Externalizing problems } \\
\hline & Model 1 & Model 2 & Model 1 & Model 2 & Model 1 & Model 2 \\
\hline \multicolumn{7}{|l|}{ Age 3} \\
\hline Paternal job loss & $-.077(.034)^{* *}$ & $-.023(.033)$ & $.105(.033)^{* * *}$ & $.059(.034)^{*}$ & $.098(.033)^{* * *}$ & $.052(.033)$ \\
\hline Maternal job loss & $.035(.046)$ & $.054(.044)$ & $.064(.045)$ & $.040(.045)$ & $.032(.045)$ & $.003(.044)$ \\
\hline \multicolumn{7}{|l|}{ Age 5} \\
\hline Paternal job loss & $-.083(.034)^{* *}$ & $-.030(.034)$ & $.025(.034)$ & $-.011(.034)$ & $.096(.033)^{* * *}$ & $.049(.033)$ \\
\hline Maternal job loss & $-.087(.046)^{*}$ & $-.070(.045)$ & $.036(.046)$ & $.010(.045)$ & $.118(.045)^{* * *}$ & $.090(.044)^{* *}$ \\
\hline$N$ & 6,303 & 6,303 & 6,303 & 6,303 & 6,303 & 6,303 \\
\hline
\end{tabular}

${ }^{*} p<.10 .{ }^{*} p<.05 .{ }^{* *} p<.01$.

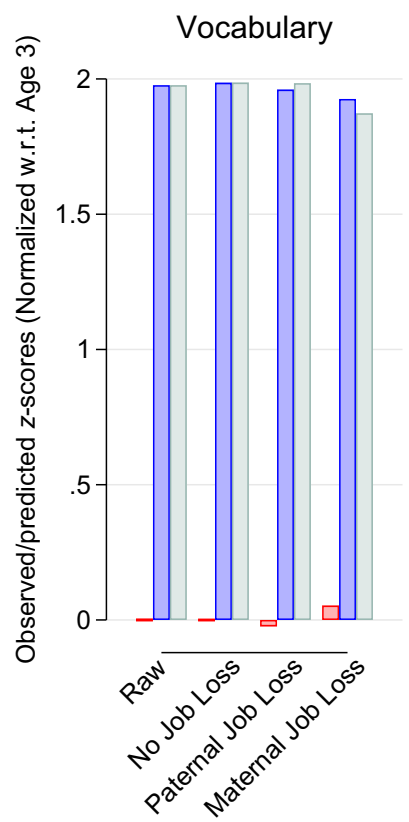

Age 3
Internalizing Problems

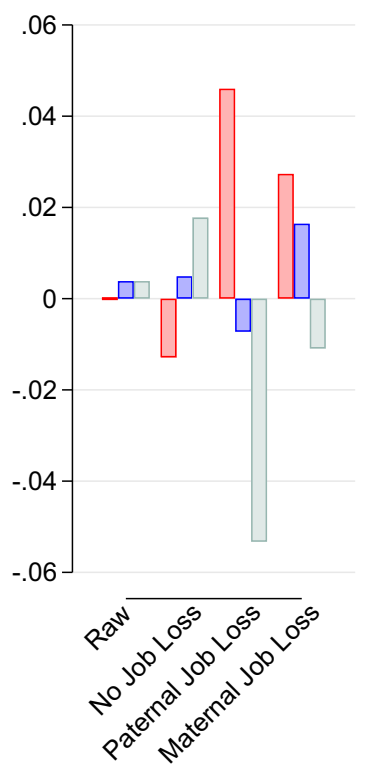

Externalizing Problems

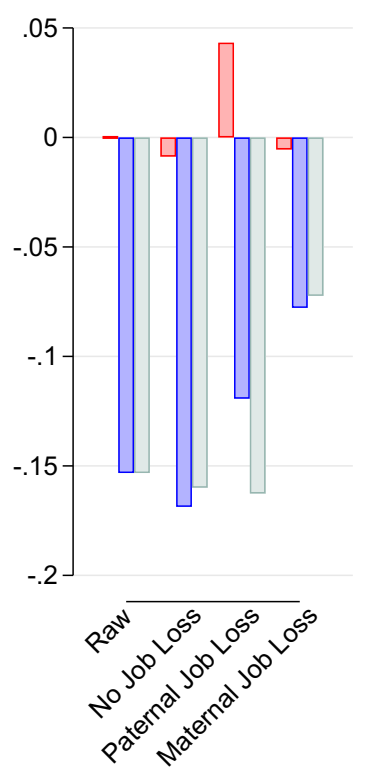

Figure 2. Observed/predicted z-scores for each child outcome at ages 3 and 5, together with the corresponding delta. All scores are normalized with respect to the outcome-specific average at age 3. Raw refers to the observed average scores in the analytical sample, No job loss refers to the predicted scores as per Equation 2 for children that did not experience parental job loss, Paternal job loss and Maternal job loss correspond to the respective predictions as per Equation 2 for children experiencing paternal/maternal job loss.

positive scores are above the age- 3 average, and negative scores are below.

For vocabulary scores in the left panel, Raw data indicate a jump of around $2 S D$ s between ages 3 and 5. This delta is similar when based on modelbased predictions under no job loss and under paternal job loss while it is somewhat lower under maternal job loss. The middle panel for internalizing problems might seem puzzling at first glance, as children in our sample experience a slight increase in scores for this outcome on average and, even more so, under no job loss. Children under paternal and maternal job loss appear to exhibit a reduction in internalizing problems from ages 3 to 5 , but this is largely a by-product of the higherthan-average scores for these same children at age 
3. Last, the third panel for externalizing problems shows that children in our sample experience a reduction in externalizing behavior of around 15\% of a $S D$ in the raw data, as well as under no job loss, and under paternal job loss-albeit the latter is a function of the higher-than-average score at age 3 . This developmental improvement, however, stops at roughly $7 \%$ of a $S D$ under maternal job loss.

On balance, we find stronger evidence for an association between parental job loss and behavioral adjustment rather than vocabulary test scores, and with externalizing problems more than internalizing problems. The associations between parental job loss and child outcomes are composite, varying across developmental domains, child age, and depending on which parent experienced job loss. Of all detrimental effects of parental job loss displayed in Table 2, those of maternal job loss, especially on externalizing problems, are also the most consequential for developmental trajectories.

\section{Mediating Pathways of Family Investment and Family Stress}

Assuming away omitted variables and related confounding bias, estimates displayed in Table 2 may be interpreted as the total causal effects of parental job loss on child outcomes. We now decompose such total effects in their direct and indirect components, investigating mediating pathways via parental income and maternal parenting.

Drops in parental income are a likely consequence of job loss. As per Equation 3, we find that paternal (maternal) job loss depresses parental income by around $18 \%(15 \%)$, estimates that are largely in line with previous studies (e.g., Davis \& Von Wachter, 2011; Jacobson et al., 1993) and that we report, for the sake of brevity, in Appendix S2 (Table 2S). In Figure 3, we examine how, through such losses in parental income, parental job loss may impinge on children's vocabulary scores. Total effects (RATEs), analogous to those in the second column of Table 2, are decomposed in their natural direct (R-NDEs) and indirect (R-NIEs) components, as per Equations 5 and 6, respectively. Similar to our main analyses, these effects are displayed for both age 3 (left panel) and age 5 (right panel).

We find that, despite the fact that total and direct effects are not detected, paternal job loss may have adverse consequences on children's vocabulary at age 3 via the channel of parental income alone. If only for parental income losses, indeed,

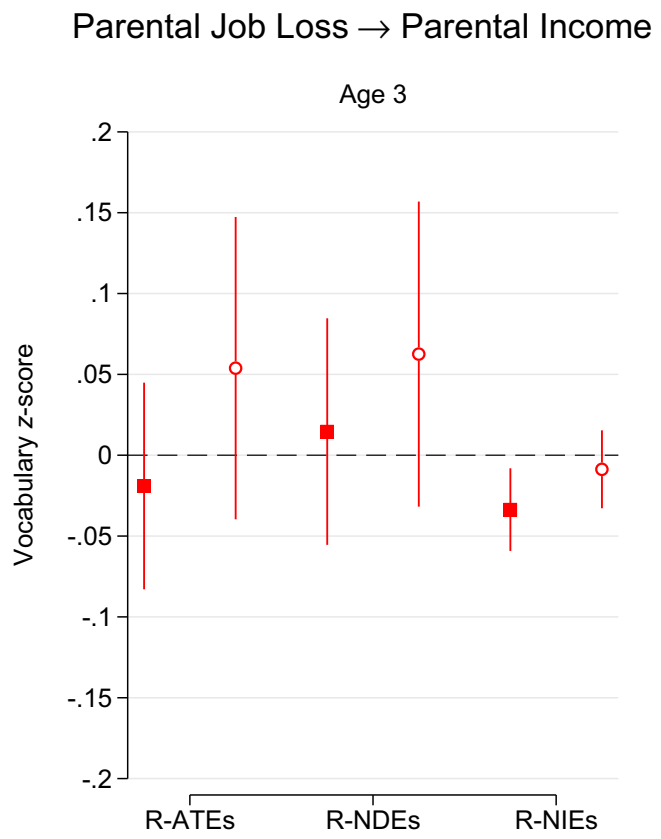

$\rightarrow$ Children's Vocabulary (z-scores)

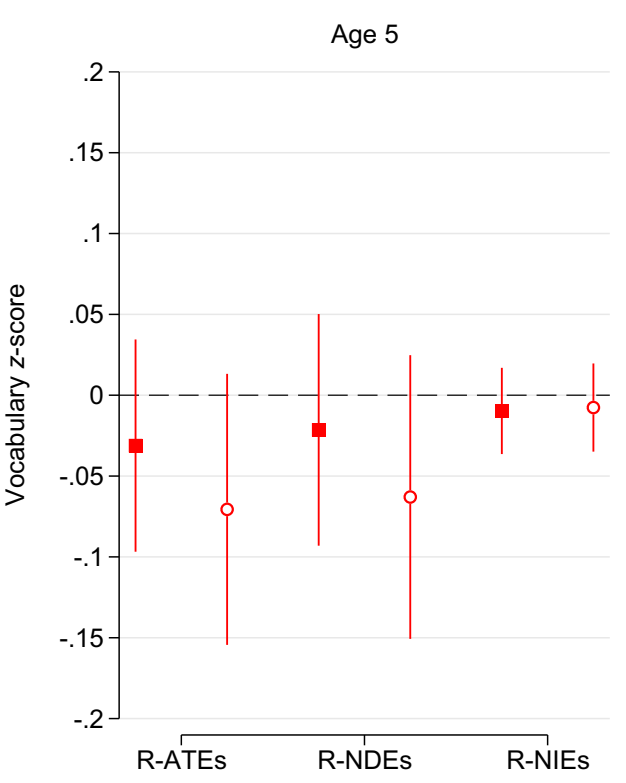

- Paternal Job Loss

- Maternal Job Loss

Figure 3. Mediation analyses for the effects of parental job loss on children's vocabulary via parental income.

Note. R-ATEs = Randomized Average Total Effects; R-NDEs = Randomized Natural Direct Effects; R-NIEs = Randomized Natural Indirect Effects. Standard errors are bootstrapped with 200 replications. 
Parental Job Loss $\rightarrow$ Maternal Negative Parenting $\rightarrow$ Children's Socio-emotional Adjustment (z-scores)

Internalizing Problems
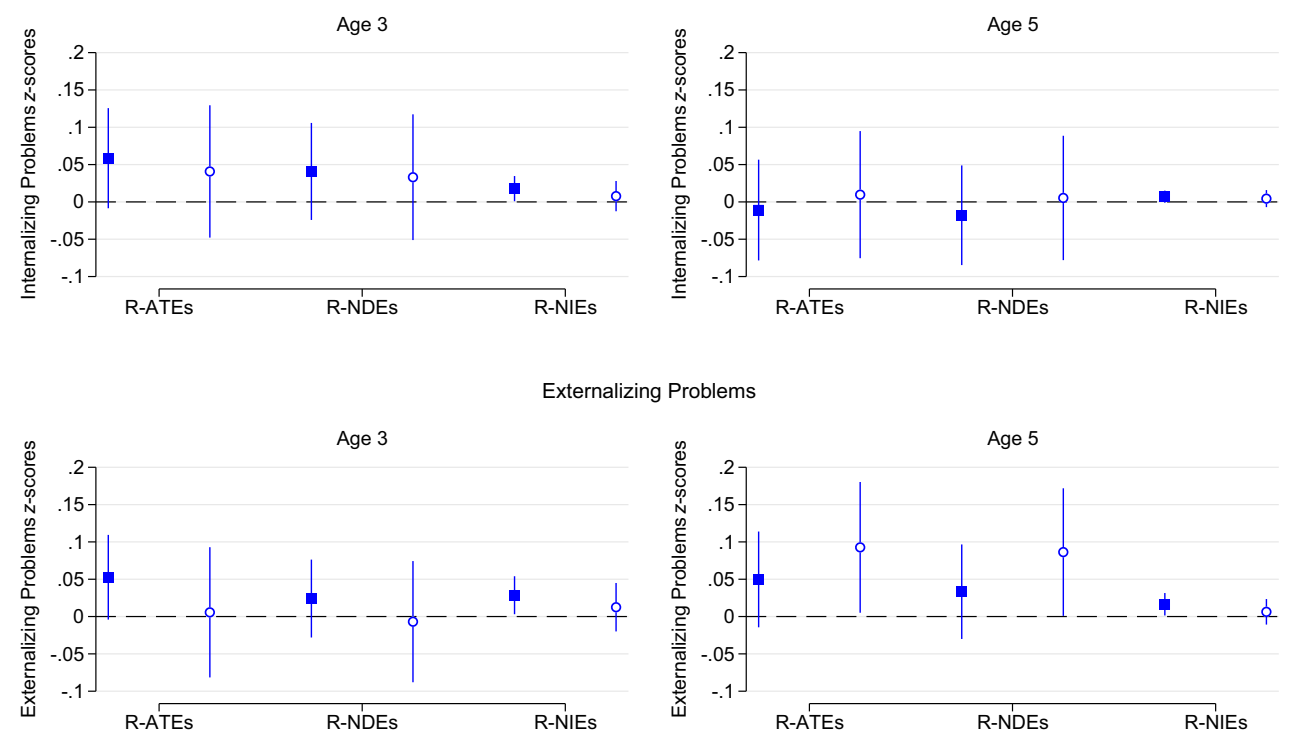

\section{- Paternal Job Loss o Maternal Job Loss}

Figure 4. Mediation analyses for the effects of parental job loss on children's internalizing and externalizing problems, via maternal negative parenting.

Note. R-ATEs = Randomized Average Total Effects; R-NDEs = Randomized Natural Direct Effects; R-NIEs = Randomized Natural Indirect Effects. Standard errors are bootstrapped with 200 replications.

paternal job loss would lead to a decrease of around .03 SDs $(p=.011)$ in children's vocabulary scores-as evidenced by the R-NIE in the left panel of Figure 3. Besides this mediation pattern, none other could be detected in Figure 3, not even for the relatively large negative effect of maternal job loss on children's vocabulary at age 5 .

Turning to problem behavior, we consider how parental job loss may hamper this developmental domain by triggering family stress, the latter being captured by maternal negative parenting. When estimating Equation 3 on this candidate mediator (see Appendix S2, Table 2S), we find that paternal job loss yields an increase of .07 SDs in maternal negative parenting $(p=.044)$. Mothers' own job loss, on the other hand, only leads to a .03 increase in the $z$-scores of maternal negative parenting ( $p=.442)$. Coherently, when looking at the mediating role of maternal negative parenting in Figure 4, we find that a cross-over effect from fathers to mothers partly explains why paternal job loss results in accrued behavioral problems in this Irish cohort.

Starting from the top half of Figure 4, we observe that children's internalizing problems increase by

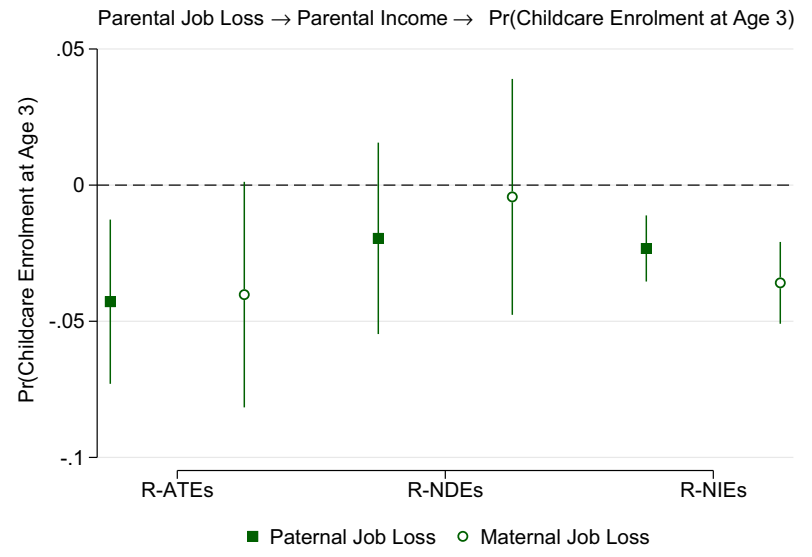

Figure 5. Mediation analyses for the effects of parental job loss on children's chances of enrolment in formal childcare, via parental income.

Note. R-ATEs = Randomized Average Total Effects; R-NDEs = Randomized Natural Direct Effects; R-NIEs = Randomized Natural Indirect Effects. Standard errors are bootstrapped with 200 replications.

around .06 SDs at age 3 in response to paternal job loss, analogously to what we displayed in the fourth column of Table 2. Moving from this R-ATE to the 
$\mathrm{R}-\mathrm{NDE}$, the direct effect, the estimate reduces to roughly .04 SDs. The indirect effect R-NIE further shows that, via its effect on maternal negative parenting alone, paternal job loss results in $.02 \mathrm{SDs}$ more in internalizing problems $(p=.040)$. A similar pattern is also found for the R-NIEs of paternal job loss on externalizing problems at age $3(.03$, $p=.029)$ and age $5(.02, p=.033)$. We could not detect, conversely, any role for maternal negative parenting in mediating the (larger) effect of maternal job loss on externalizing problems at age 5 .

So far, we have paired together parental income and cognitive development, and negative parenting and behavioral development, following previous studies (e.g., Yeung et al., 2002). In Appendix S3, we explore crossing mediators and outcomes to provide a complete, and perhaps more integrated, account of family investment and family stress dynamics (e.g., Layte, 2017). As displayed in Supporting Information (Figure 1S) though, we could not detect any indirect effect flowing from parental job loss to cognitive development via maternal negative parenting. Differently, for both internalizing and externalizing problems at age 3 , we find some role for parental income differences, as triggered by paternal job loss. Via this channel alone, and thus looking at the R-NIEs in Supporting Information (Figure 2S), internalizing problems at age 3 increase by $.03 S D s(p=.058)$ and externalizing problems by .04 SDs $(p=.008)$.

\section{Delving Into the Mechanisms: Childcare Enrolment and Heterogeneous Effects}

Our mediation analyses suggest that parental income differences associated with job displacement might harm children across multiple developmental domains and especially so at age 3 . Yet, particularly for vocabulary scores at age 3 , the negative indirect effects via parental income are coupled with noisy estimates of the total and direct effects of job loss, the latter turning out even positive for maternal job loss. To make sense of these patterns, we performed a number of complementary analyses.

First, our hunch is that these negative indirect effects via parental income express a reduced ability among families to enroll children into formal childcare. We therefore examined if parental job loss affected the chances of attending formal childcare among this Irish cohort during the Great Recession, and to what extent this relates to income losses. We ran a new mediation analysis, in line with the procedures followed throughout the paper but with enrolment in formal childcare at the age of 3 as the main outcome (coded 1 if the child is enrolled at Wave 2, 0 otherwise).

Results displayed in Figure 5 support our expectation. To begin with the total effects (RATEs), children's chances of being enrolled in formal childcare are roughly 4 percentage points lower in response to both paternal $(p=.005)$ and to maternal job loss $(p=.057)$, as compared to households in which no job loss occurred. Direct effects or RNDEs, operating via all other channels but that of parental income, are substantially smaller. Indirect effects conversely show that, for a change in parental income such as that triggered by job loss, the chances to be enrolled in childcare decrease by around 2 percentage points for paternal job loss $(p<.001)$ and 4 percentage points for maternal job loss $(p<.001)$.

In light of such forgone investments in formal childcare, parents may compensate with investments of their own, for example spending more time in educational activities with their children. This could explain why some of the total and direct effects of job loss are null or even positive, when it comes to children's verbal ability at age 3 . It could be though that parental educational inputs might better substitute those from formal childcare when parents are affluent or highly educated (e.g., Fort et al., 2020). Hence, lacking data on time spent on specific parent-child activities, we performed a second round of additional analyses splitting our sample by maternal education, to gauge possible compensation patterns.

All our analyses split by maternal education are presented and discussed more at length in Appendix S4. In short, and perhaps unexpectedly, we do find that compensation for a lack of investment in formal childcare is more plausible for children whose mother had upper-secondary education at most, rather than a tertiary degree. In households where mothers have no more than high-school diplomas, indeed, we find a large and positive direct effect of maternal job loss on children's vocabulary score at age $3(.19 S D s, p=.012)$, as per Supporting Information (Figure 3S). This is coupled with a negative indirect effect of maternal job loss via parental income $(-.07 S D s, p=.004)$, a combination we cannot detect for households in which the mother has tertiary education. Differently, for paternal job loss, we find negative indirect effects of paternal job loss on vocabulary scores at age 3, flowing via income losses and similarly so regardless of maternal education. For problem behavior, in Supporting Information (Figures $4 S$ and 5S), we typically find larger associations in households with higher maternal education. 
Furthermore, moving on to Supporting Information (Figure 6S), maternal job loss is associated with the largest total drop in the chances of childcare enrolment at age 3 ( -9 percentage points, $p=.005$ ), when the mother has upper-secondary education or less. This partly flows via income losses, looking at the indirect effect or R-NIE $(\approx-2$ percentage points, $p=.044)$. Taken together, these estimates support the idea of some compensatory investment at age 3 by displaced mothers with lower education in our sample. At the same time, income-related indirect effects on childcare enrolment are invariably negative and similar in size, across sub-samples split by maternal education and regardless of which parent was displaced.

If we take lower maternal education as a proxy of disadvantage at the baseline, parental job loss does not only affect the least well-off households in our sample. Rather, detrimental effects are found across households for both verbal ability and childcare enrolment, whereas estimates for problem behavior are, if anything, larger in households with higher maternal education.

\section{Discussion}

Overall, we find evidence linking parental job loss and early child development in a recent Irish cohort. Parental job loss seems to affect problem behavior more than verbal ability, and externalizing problems in particular. For verbal ability, however, null total effects hide composite direct and indirect effects that emerge through our effect decomposition. The latter suggests that, if only via parental income, children of displaced fathers would lag behind in their verbal ability at age 3. Similar, via the same channel alone, children of displaced mothers-particularly of those with high school or lesswould also lag behind if not for some "compensatory" effect via unobserved channels. A reduced capacity to invest in formal childcare, due to job and income losses, might further explain these patterns. We also find some role for negative parenting, as triggered by job loss, in explaining behavioral problems in children of displaced parents. Notably though, income losses are found to matter to a similar or larger degree than parenting when it comes to behavioral problems. Findings for parenting should also be taken with caution due to the potential for common-method bias and reverse causation with children's behavior, two issues that are less likely to affect our measures of the investment channel.
On balance, whether total, direct, or indirect, the effects of parental job loss reach at most one-tenth of a standard deviation for any given child outcome in our study. To the best of our knowledge, only Peters (2016) similarly considered development in pre-school age, finding associations up to five times larger than ours when focusing on maternal job loss and total SDQ scores in a small German sample. Differences in sample size and construction, context, exposure and outcome definitions, could all be at play. Evidence from multiple large and diverse samples is paramount to get a clearer picture. Related, even our sample is not large enough to assess effect modification by race/ethnicity, for example, in part due to differential loss to followup. Generalizability, hence, should be taken with some caution: considering recent evidence on the stratification of responses to income shocks (Ganong et al., 2020), job loss being one such shock, it could be that our study identifies lower bounds of the effects of displacement passing through parental income.

We note that our estimates are, nonetheless, similar in magnitude to those for other "economic" inputs into child development (e.g., Khanam \& Nghiem, 2016; Washbrook et al., 2014) and of larger substantial significance than those identified for parental job loss and children's physical health in this Irish cohort (Reinhard et al., 2018). Estimates might be small in an absolute sense, yet we could not model a possible accumulation of effects depending on the length of job displacement (e.g., Hill et al., 2011), and future studies could shed light on this. Additionally, our reference group might comprise households that, while untouched by job loss, might have been nonetheless hit by the recession, for example via cuts in wages or public services (Whelan, Russell, \& Maître, 2016). If such facets of economic hardship also hamper child development, contrasting them with job loss in this cohort might have provided us, once again, with lower bounds for the effects of parental job loss on early child development.

Our estimates can also be granted a causal interpretation, but only to the extent we sufficiently addressed confounding bias. Differently from previous studies, we address potential sources of postexposure confounding in the form of family behavior that might follow job loss (separations, additional parities, family moves). Nonetheless, our analyses might be biased by unmeasured common causes of our exposure, outcomes, and mediators. If robust to such lurking variables, our study highlights how more generous income support to 
displaced parents might have developmental benefits for their children. In particular, we suggest that subsidizing childcare expenses might mitigate the adverse effects of job loss across socio-economic strata, particularly on verbal ability and problem behavior at age 3 . This finding may reflect two features of the Great Recession in Ireland, namely its adverse impact on the middle class, on the one hand, and the cuts to already expensive childcare arrangements on the other (Nolan \& Maître, 2017; Whelan \& Maître, 2014). More broadly, our results speak to previous studies showing how income losses due to job displacement might be more consequential when timed around a specific parental investment in formal education. While previous studies ascertained this for secondary and tertiary education (Coelli, 2011; Schmidpeter, 2020), we provide evidence for pre-school education in the form of childcare enrolment.

In one instance, we found evidence of some form of parental compensation counteracting the adverse effects of job loss on verbal ability. Unexpected, this finding is our most exploratory one and would warrant further inquiry. We can speculate that time investments in educational activities might be key in such compensatory efforts (as suggested, e.g., by Schaller \& Zerpa, 2019, p. 10). Children reap benefits from parental time in educational activities especially when it comes to cognitive ability and returns to such activities are similar regardless of parental education (e.g., Cano, 2019; Hsin \& Felfe, 2014). Furthermore, previous research has found that mothers with lower educational attainment are less able to combine their often inflexible work schedules and such "productive" childcare (Hsin \& Felfe, 2014). Finding that, for such mothers, job loss per se improves their children's vocabulary scores coherently suggests that job loss might free up time to make time investments in children's education. At the same time, such compensation is at best narrow in scope, as we do find "uncompensated" detrimental effects of maternal job loss on verbal ability and externalizing problems at a later age. One possible reason is that time investments, even if conceived as compensatory by parents, might not necessarily be beneficial when accompanied by stress, possibly heightened by job loss. Future studies could thus further examine not just trade-offs between formal and informal childcare after job loss but also those between parental time and parental stress.

Further work on mechanisms can also inform what can be done to address the developmental consequences of job loss and other economic shocks. As per Figure 2, total effects in our study imply a notable developmental lag in terms of externalizing behavior by age 5 , for children exposed to maternal job loss. This is largely unexplained by our mediation analysis, not via parental income and thus also childcare enrolment by age 3, nor via our measure of maternal negative parenting. Future studies could examine alternative aspects of parenting-some, like sensitivity, already being linked to maternal job loss (Prickett, 2020) and externalizing behavior (e.g., Pinquart, 2017b) or investigate different operationalizations of the stress channel (e.g., parental depression, parenting stress, parents' relationship satisfaction) and of the investment channel (e.g., childcare quality, home environment). Another possibility we leave to further inquiry is that the effects of job loss on candidate mediators take (more) time to mature, or that heightened parental and child responses to job loss are elicited by longer spells of joblessness-which we could not track.

This could further inform effective interventions that stave off the effects that may precipitate from externalizing behavior, a known correlate of inferior health and educational attainment in adolescence and adulthood (e.g., Currie, 2009; Goodman et al., 2010; Papageorge, Ronda, \& Zheng, 2019). Previous studies found that externalizing problems may improve following unconditional monetary transfers (Milligan \& Stabile, 2011) or sustained parenting interventions such as the Preparing for Life program (Doyle, 2020), but our results should issue caution on whether these would be effective if targeted specifically to displaced parents.

\section{Concluding Remarks}

These limitations notwithstanding, our work is among the first to assess how parental job loss may affect children's cognitive and behavioral development around pre-school years. Our findings may bear significance for the larger literature on the intergenerational effects of job loss. By disentangling composite direct and indirect effects, we suggest that formal mediation analyses may contribute to the literature in the field. Previous studies on long-term effects have suggested that income losses play only a little role for the outcomes of children whose parents were displaced (e.g., Bratberg et al., 2008; Hilger, 2016; Rege et al., 2011). The same conclusion was drawn for problem behaviors at an early age and maternal job loss (Peter, 2016). More broadly, research has questioned just how "productive" parental income can be for child development (e.g., Mayer, 1997). We highlight that, when 
isolated, negative indirect effects via parental income can be detected for both cognitive and behavioral development. Maternal negative parenting matters, to an extent, only when it comes to behavioral problems. Our analyses thus show how family investment and family stress channels may co-exist and shape early development in response to adverse economic circumstances. This may provide a further piece of evidence supporting "integrated" or "hybrid" accounts of how investment and stress contribute to children's life chances, in line with appraisals in developmental psychology (Conger \& Donnellan, 2007), sociology (Layte, 2017), and economics (Cobb-Clark, Salamanca, \& Zhu, 2019).

Associations between parental job loss and problem behaviors hold promise to shed light on longterm intergenerational effects too. Previous research has found negative effects on school performance, but only mixed evidence for a (negative) effect of parental job loss on children's future earnings (Bratberg et al., 2008; Gregg et al., 2012; Hilger, 2016). We show that parental job loss may be associated with multiple behavioral problems at an early age, and recent research suggests that internalizing and externalizing behaviors may have opposite returns in school and the labor market (Papageorge et al., 2019). In addition, in line with a number of previous studies (Hill et al., 2011; Peter, 2016), we find that the strongest behavioral responses in children stem from maternal job loss, whilst long-run studies have typically focused on paternal job loss. Future research could thus benefit from considering early child development as part of the process by which the effects of both paternal and maternal job loss reach across generations.

This study contributes to our understanding of family processes during times of economic hardship, suggesting which policy levers might help undo the intergenerational toll of parental job loss. During the first months of 2020, Ireland began facing the fallout of a global pandemic. Based on claims of the new Pandemic Unemployment Payment, unemployment is estimated to have soared to $16.5 \%$ in March 2020 (Central Statistics Office [CSO], 2020), a figure already higher than the peak reached during the Great Recession. The scale, patterns, and consequences of this new wave of job loss are still emerging, in Ireland and worldwide. Among others, the intergenerational consequences of job loss are salient, therefore, and easing childcare costs might be an important part, at least in the short run, of future policy responses directed at families facing hardship.

\section{References}

Bates, J. E., Freeland, C. A. B., \& Lounsbury, M. L. (1979). Measurement of infant difficultness. Child Development, 50, 794-803. https://doi.org/10.2307/1128946

Becker, G., \& Tomes, N. (1986). Human capital and the rise and fall of families. Journal of Labor Economics 4(3, Pt. 2), S1-S39. https:/ / doi.org/10.1086/298118

Billari, F. C., \& Liefbroer, A. C. (2010). Towards a new pattern of transition to adulthood? Advances in Life Course Research, 15(2-3), 59-75. https://doi.org/10. 1016/j.alcr.2010.10.003

Bratberg, E., Nilsen, Ø. A., \& Vaage, K. (2008). Job losses and child outcomes. Labour Economics, 15, 591-603. https: / / doi.org/10.1016/j.labeco.2008.04.006

Browne, J., \& Neumann, D. (2017). OECD tax wedge and effective tax rates on labour: Childcare costs in 2015. OECD No. VS/2015/0427 (DI150030). Retrieved from https: / taxben.oecd.org/tax-ben-resources/Childcarecosts-in-2015.pdf

Cano, T. (2019). Changes in fathers' and mothers' time with children: Spain, 2002-2010. European Sociological Review, 35, 616-636. https://doi.org/10.1093/esr/jc z020

Central Statistics Office [CSO]. (2009). Report on vital statistics. Dublin, Ireland: Stationery Office. Retrieved from https://www.cso.ie/en/media/csoie/releasespub lications/documents/vitalstats/2009/annualreport2009. pdf

Central Statistics Office [CSO]. (2020). Monthly unemployment 2020. Statistical release, 09 April 2020. Retrieved from https://www.cso.ie/en/releasesandpublications / er/mue/monthlyunemploymentmarch2020/

Charkaluk, M.-L., Rousseau, J., Calderon, J., Bernard, J. Y., Forhan, A., Heude, B., ... EDEN Mother-Child Cohort Study Group. (2017). Ages and stages questionnaire at 3 years for predicting IQ at 5-6 years. Pediatrics, 139, e20162798. https://doi.org/10.1542/peds. 2016-2798

Cobb-Clark, D. A., Salamanca, N., \& Zhu, A. (2019). Parenting style as an investment in human development. Journal of Population Economics, 32, 1315-1352. https:// doi.org/10.1007/s00148-018-0703-2

Coelli, M. B. (2011). Parental job loss and the education enrollment of youth. Labour Economics, 18(1), 25-35. https: / / doi.org/10.1016/j.labeco.2010.04.015

Condon, J. T., \& Corkindale, C. J. (1998). The assessment of parent-to-infant attachment: Development of a selfreport questionnaire instrument. Journal of Reproductive and Infant Psychology, 16(1), 57-76. https://doi.org/10. $1080 / 02646839808404558$

Conger, R. D., \& Donnellan, M. B. (2007). An interactionist perspective on the socioeconomic context of human development. Annual Review of Psychology, 58, 175-199. https://doi.org/10.1146/annurev.psych.58.110405. 085551

Conti, G., \& Heckman, J. J. (2014). Economics of child well-being. In A. Ben-Arieh, F. Casas, I. Frønes, \& 
J. Korbin (Eds.), Handbook of child well-being (pp. 363-401). Dordrecht, The Netherlands: Springer.

Currie, J. (2009). Healthy, wealthy, and wise: Socioeconomic status, poor health in childhood, and human capital development. Journal of Economic Literature, 47, 87-122. https://doi.org/10.1257/jel.47.1.87

Davis, S. J., \& Von Wachter, T. (2011). Recessions and the costs of job loss. Brookings Papers on Economic Activity, 42(2), 1-72. https://doi.org/10.3386/w17638

Doyle, O. (2020). The first 2,000 days and child skills. Journal of Political Economy, 128, 2067-2122. https://doi. org/10.1086/705707

Duncan, G. J., \& Magnuson, K. (2013). Investing in preschool programs. Journal of Economic Perspectives, 27, 109-132. https://doi.org/10.1257/jep.27.2.109

Elliott, C. D., Smith, P., \& McCulloch, K. (1997). British Ability Scales second edition (BAS II): Technical manual. London, UK: NFER-Nelson.

Fort, M., Ichino, A., \& Zanella, G. (2020). Cognitive and noncognitive costs of day care at age 0-2 for children in advantaged families. Journal of Political Economy, 128, 158-205. https://doi.org/10.1086/704075

Ganong, P., Jones, D., Noel, P. J., Greig, F. E., Farrell, D., \& Wheat, C. (2020). Wealth, race and consumption smoothing of typical income shocks. NBER Working Paper 27552. https://doi.org/10.3386/w27552

Gershoff, E. T., Aber, J. L., Raver, C. C., \& Lennon, M. C. (2007). Income is not enough: Incorporating material hardship into models of income associations with parenting and child development. Child Development, 78(1), 70-95. https://doi.org/10.1111/j.1467-8624.2007.00986.x

Goodman, A., \& Goodman, R. (2009). Strengths and Difficulties Questionnaire as a dimensional measure of child mental health. Journal of the American Academy of Child $\mathcal{E}$ Adolescent Psychiatry, 48, 400-403. https://doi.org/ 10.1097/CHI.0b013e3181985068

Goodman, A., Lamping, D. L., \& Ploubidis, G. B. (2010). When to use broader internalising and externalising subscales instead of the hypothesised five subscales on the Strengths and Difficulties Questionnaire (SDQ): Data from British parents, teachers and children. Journal of Abnormal Child Psychology, 38, 1179-1191. https:// doi.org/10.1007/s10802-010-9434-x

Grant, K. E., Compas, B. E., Stuhlmacher, A. F., Thurm, A. E., McMahon, S. D., \& Halpert, J. A. (2003). Stressors and child and adolescent psychopathology: Moving from markers to mechanisms of risk. Psychological Bulletin, 129, 447. https:/ / doi.org/10.1037/0033-2909.129.3.447

Gregg, P., Macmillan, L., \& Nasim, B. (2012). The impact of fathers' job loss during the recession of the 1980s on their children's educational attainment and labour market outcomes. Fiscal Studies, 33, 237-264. https://doi. org/10.1111/j.1475-5890.2012.00160.x

Heckman, J. J., Stixrud, J., \& Urzua, S. (2006). The effects of cognitive and noncognitive abilities on labor market outcomes and social behavior. Journal of Labor Economics, 24, 411-482. https://doi.org/10.1086/ 504455
Hilger, N. G. (2016). Parental job loss and children's longterm outcomes: evidence from 7 million fathers' layoffs. American Economic Journal: Applied Economics, 8, 247-283. https:/ / doi.org/10.1257/app.20150295

Hill, H. D., Morris, P. A., Castells, N., \& Walker, J. T. (2011). Getting a job is only half the battle: Maternal job loss and child classroom behavior in low-income families. Journal of Policy Analysis and Management, 30, 310-333. https://doi.org/10.1002/pam.20565

Hill, V. (2005). Through the past darkly: A review of the British Ability Scales second edition. Child and Adolescent Mental Health 10, 87-98. https://doi.org/10.1111/j. 1475-3588.2004.00123.x

Hinshaw, S. P., Owens, E. B., Wells, K. C., Kraemer, H. C., Abikoff, H. B., Arnold, L. E., ... Hoza, B. (2000). Family processes and treatment outcome in the MTA: Negative/ ineffective parenting practices in relation to multimodal treatment. Journal of Abnormal Child Psychology, 28, 555-568. https://doi.org/10.1023/a:1005183115230

Hsin, A., \& Felfe, C. (2014). When does time matter? Maternal employment, children's time with parents, and child development. Demography, 51, 1867-1894. https:/ / doi.org/10.1007/s13524-014-0334-5

Huttunen, K., Møen, K., \& Salvanes, K. G. (2018). Job loss and regional mobility. Journal of Labor Economics, 36, 479-509. https: / / doi.org/10.1086/694587

Jacobson, L. S., LaLonde, R. J., \& Sullivan, D. G. (1993). Earnings losses of displaced workers. The American Economic Review, 83, 685-709.Retrieved from https:// www.jstor.org/stable/2117574

Khanam, R., \& Nghiem, S. (2016). Family income and child cognitive and noncognitive development in Australia: Does money matter? Demography, 53, 597-621. https:/ / doi.org/10.1007/s13524-016-0466-x

Kiernan, K. E., \& Huerta, M. C. (2008). Economic deprivation, maternal depression, parenting and children's cognitive and emotional development in early childhood. The British Journal of Sociology, 59, 783-806. https://doi. org/10.1111/j.1468-4446.2008.00219.x

Kühhirt, M., \& Klein, M. (2018). Early maternal employment and children's vocabulary and inductive reasoning ability: A dynamic approach. Child Development, 89, e91-e106. https://doi.org/10.1111/cdev.12796

Layte, R. (2017). Why do working-class kids do worse in school? An empirical test of two theories of educational disadvantage. European Sociological Review, 33, 489-503. https://doi.org/10.1093/esr/jcx054

Layte, R., \& McCrory, C. (2018). Fiscal crises and personal troubles: The Great Recession in Ireland and family processes. Social Psychiatry and Psychiatric Epidemiology, 53, 987-1001. https://doi.org/10.1007/s00127-018-15519

Leibowitz, A. (1974). Home investments in children. Journal of Political Economy, 82(2, Pt. 2), S111-S131. https:/ / doi.org/10.1086/260295

Lindo, J. M. (2011). Parental job loss and infant health. Journal of Health Economics, 30, 869-879. https://doi. org/10.1016/j.jhealeco.2011.06.008 
Marcus, J. (2013). The effect of unemployment on the mental health of spouses-Evidence from plant closures in Germany. Journal of Health Economics, 32, 546-558. https:/ / doi.org/10.1016/j.jhealeco.2013.02.004

Mayer, S. E. (1997). What money can't buy: Family income and children's life chances, Cambridge, Mass: Harvard University Press.

McCrory, C., Williams, J., Murray, A., Quail, A., \& Thornton, M. (2013). Growing Up in Ireland national longitudinal study of children: Infant cohort. Design, instrumentation and procedures for the infant cohort at wave two (3 years). Dublin, Ireland: Department of Children and Youth Affairs.

McLoyd, V. C., Jayaratne, T. E., Ceballo, R., \& Borquez, J. (1994). Unemployment and work interruption among African American single mothers: Effects on parenting and adolescent socioemotional functioning. Child Development, 65, 562-589. https://doi.org/10.1111/j.14678624.1994.tb00769.x

Mendolia, S. (2014). The impact of husband's job loss on partners' mental health. Review of Economics of the Household, 12, 277-294. https://doi.org/10.1007/ s11150-012-9149-6

Milligan, K., \& Stabile, M. (2011). Do child tax benefits affect the well-being of children? Evidence from Canadian child benefit expansions. American Economic Journal: Economic Policy, 3, 175-205. https://doi.org/10. 1257/pol.3.3.175

Nolan, B., \& Maître, B. (2017). Children of the celtic tiger during the economic crisis: Ireland. In B. Cantillon, Y. Chzhen, S. Handa, \& B. Nolan (Eds.), Children of austerity. Impact of the great recession on child poverty in rich countries (pp. 146-169). Oxford, UK: UNICEF \& Oxford University Press.

Oreopoulos, P., Page, M., \& Stevens, A. H. (2008). The intergenerational effects of worker displacement. Journal of Labor Economics, 26, 455-483. https://doi.org/10. 1086/588493

Papageorge, N. W., Ronda, V., \& Zheng, Y. (2019). The economic value of breaking bad: Misbehavior, schooling and the labor market. NBER Working Paper No. 25602.

Peter, F. (2016). The effect of involuntary maternal job loss on children's behaviour and non-cognitive skills. Labour Economics, 42, 43-63. https://doi.org/10.1016/j. labeco.2016.06.013

Pinquart, M. (2017a). Associations of parenting dimensions and styles with internalizing symptoms in children and adolescents: A meta-analysis. Marriage $\mathcal{E}$ Family Review, 53, 613-640. https://doi.org/10.1007/ s10648-015-9338-y

Pinquart, M. (2017b). Associations of parenting dimensions and styles with externalizing problems of children and adolescents: An updated meta-analysis. Developmental Psychology, 53, 873-932. https://doi.org/10. $1037 /$ dev0000295

Prickett, K. C. (2020). Mothers' job loss and their sensitivity to young children's development. Child Development, 91, 1970-1987. https://doi.org/10.1111/cdev.13398
Psychogiou, L., Daley, D., Thompson, M., \& SonugaBarke, E. (2007). Testing the interactive effect of parent and child ADHD on parenting in mothers and fathers: A further test of the similarity-fit hypothesis. British Journal of Developmental Psychology, 25, 419-433. https:/ / doi.org/10.1348/026151006X170281

Radloff, L. S. (1977). The CES-D scale: A self-report depression scale for research in the general population. Applied Psychological Measurement, 1, 385-401. https:// doi.org/10.1177/014662167700100306

Rege, M., Telle, K., \& Votruba, M. (2011). Parental job loss and children's school performance. The Review of Economic Studies, 78, 1462-1489. https://doi.org/10. $1093 /$ restud/rdr002

Reinhard, E., Layte, R., McCrory, C., Panico, L., \& Avendano, M. (2018). The Great recession and the health of young children: A fixed-effects analysis in Ireland. American Journal of Epidemiology, 187, 1438-1448. https: / / doi.org/10.1093/aje/kwy001

Robins, J. M., Hernan, M. A., \& Brumback, B. (2000). Marginal structural models and causal inference in epidemiology. Epidemiology, 11, 551-560. https://doi.org/ 10.1097/00001648-200009000-00011

Savage, M., Callan, T., Nolan, B., \& Colgan, B. (2019). The Great Recession, austerity and inequality: Lessons from Ireland. Review of Income and Wealth, 65, 312-336. https: / / doi.org/10.1111/roiw.12337

Schaller, J., \& Zerpa, M. (2019). Short-run effects of parental job loss on child health. American Journal of Health Economics, 5(1), 8-41. https://doi.org/10.1162/ajhe_a_ 00106

Schmidpeter, B. (2020). The long-term labor market effects of parental unemployment. Upjohn Institute Working Paper 20-322. https://doi.org/10.17848/wp20-322

Seaman, S. R., \& White, I. R. (2013). Review of inverse probability weighting for dealing with missing data. Statistical Methods in Medical Research, 22, 278-295. https: / / doi.org/10.1177/0962280210395740

Squires, J., Bricker, D., \& Potter, L. (1997). Revision of a parent-completed developmental screening tool: Ages and Stages Questionnaires. Journal of Pediatric Psychology, 22, 313-328. https://doi.org/10.1093/jpepsy/22.3. 313

Stevens, A. H., \& Schaller, J. (2011). Short-run effects of parental job loss on children's academic achievement. Economics of Education Review, 30, 289-299. https://doi. org/10.1016/j.econedurev.2010.10.002

VanderWeele, T. (2015). Explanation in causal inference: Methods for mediation and interaction. Oxford, UK: Oxford University Press.

Washbrook, E., Gregg, P., \& Propper, C. (2014). A decomposition analysis of the relationship between parental income and multiple child outcomes. Journal of the Royal Statistical Society: Series A (Statistics in Society), 177, 757-782. https://doi.org/10.1111/rssa.12074

Watson, D., Whelan, C. T., Maître, B., \& Williams, J. (2015). Family economic vulnerability \& the Great Recession: An analysis of the first two waves of the Growing Up in 
Ireland study. Longitudinal and Life Course Studies, 6, 230-244. https://doi.org/10.14301/1lcs.v6i3.331

Whelan, C. T., \& Maître, B. (2014). The Great Recession and the changing distribution of economic vulnerability by social class: The Irish case. Journal of European Social Policy, 24, 470-485. https://doi.org/10.1177/ 0791603516657346

Whelan, C. T., Russell, H., \& Maître, B. (2016). Economic stress and the Great Recession in Ireland: Polarization, individualization or 'middle class squeeze'? Social Indicators Research, 126, 503-526. https://doi.org/10.1007/ s11205-015-0905-x

Wodtke, G. T., \& Zhou, X. (2020). Effect decomposition in the presence of treatment-induced confounding: A regression-with-residuals approach. Epidemiology, 31, 369-375. https: / / doi.org/10.1097/EDE.0000000000001168

Yeung, W. J., Linver, M. R., \& Brooks-Gunn, J. (2002). How money matters for young children's development: Parental investment and family processes. Child Development, 73, 1861-1879. https://doi.org/10.1111/14678624.t01-1-00511
Zubrick, S. R., Lucas, N., Westrupp, E. M., \& Nicholson, J. M. (2013). Parenting measures in the Longitudinal Study of Australian Children: Construct validity and measurement quality, Waves 1 to 4 . Canberra, ACT: Department of Social Services.

\section{Supporting Information}

Additional supporting information may be found in the online version of this article at the publisher's website:

Appendix S1. Weighting for Loss to Follow-Up and Complete-Case Analysis

Appendix S2. Main Effects of Parental Job Loss on Candidate Mediators

Appendix S3. Crossing Mediators and Outcomes Appendix S4. Heterogeneous Effects by Maternal Education 